\title{
THEORETICAL STUDIES ON THE METHODOLOGICAL PROCEDURES OF RADIATION BREEDING
}

\section{PROCEDURES FOR OBTAINING AT LEAST TWO DESIRABLE MUTANTS IN AUTOGAMOUS PLANTS FOLLOWING SEED IRRADIATION}

\author{
YOSHIO YOSHIDA \\ Kyushu Agricultural Experiment Station, Chikugo, Fukuoka-Pref., Japan
}

Received 27.vii. 64

\section{INTRODUCTION}

In the first and the second reports of this series, theoretical considerations were made on properties of the four methods for selection in irradiated populations. Each of those methods, i.e. the "improved ear-to-row method " (method B), the " one-plant-one-grain method" $(\operatorname{method} \mathrm{C})$, the "one-plant-two-grain method" (method D) and the "one-plant-three-grain method" (method E) was shown to be more effective for detecting at least one desirable plant in $\mathrm{X}_{2}$-generation as compared with the "conventional ear-to-row method". A desirable mutant is defined in this report as well as in the previous one (see Yoshida, I962).

In identifying a desirable mutant in field experiments of selection, it is frequent to face the difficulties caused by the factors such as soil heterogenity and other environmental variabilities. Therefore, under such difficult conditions for selecting a desirable mutant, it seems to be appropriate to consider the probability of detecting at least two desirable mutants in order to guarantee the detection of at least one desirable mutant.

In the present report, it is intended to establish methods for the discovery of two or more desirable mutants in $\mathrm{X}_{2}$ from a minimum total of $\mathrm{X}_{2}$-plants, and/or $\mathrm{X}_{1^{-}}$and $\mathrm{X}_{2}$-plants in the aggregate which will economise both labour and land.

\section{MATHEMATICAL PROCEDURES AND RESULTS}

(i) Explanation of notations

The symbols used in this report are explained below.

Let $p_{1}$ stand for a probability of occurrence of an $\mathrm{X}_{2}$-line containing at least one desirable mutant. From the result observed by Gaul (1958), it is possible to say that $p_{1}$ increases when $\mathrm{X}_{1}$-plants are grown densely. Let $p_{2}$ stand for a conditional probability of occurrence of such desirable mutant for every one of the plants in such an $\mathrm{X}_{2}$-line and let $q_{1}=\mathrm{I}-p_{1}$ and $q_{2}=\mathrm{I}-p_{2}$.

Let $m$ be the number of $\mathbf{X}_{2}$-lines or of $\mathrm{X}_{1}$-plants (in case of taking seeds from one ear of one $\mathrm{X}_{1}$-plant) and $n$ be the number of plants in 
an $\mathbf{X}_{2}$-line. Therefore, the product $m n$ is the total number of $\mathbf{X}_{2}$-plants.

Let $\mathrm{P}_{1}^{\mathrm{iI}}$ be the probability of detecting at least two desirable mutants among $m n$ plants. This $\mathrm{P}_{1}^{\mathrm{II}}$ is concerned in the following three different ways: (a) $\mathrm{P}_{11}^{\mathrm{II}}$; the probability of detecting at least one $\mathrm{X}_{2}$-line containing at least two desirable mutants, $(b) \mathrm{P}_{12}^{11}$; the probability of detecting at least two $\mathrm{X}_{2}$-lines (which contain at least one desirable mutant per line) among $m$ lines and $(c) \mathrm{P}_{13}^{\mathrm{II}}$; the probability of detecting at least two desirable mutants from the whole of an $\mathrm{X}_{2}$-population. In this report, it is assumed that the probability of producing a desirable mutant is equal to that of detecting a desirable mutant.

\section{(ii) Improved ear-to-row method II (method B II)}

In the first place, the effective procedure will be established by adopting $\mathrm{P}_{11}^{\mathrm{II}}$ for the aim of detecting at least one $\mathrm{X}_{2}$-line containing at least two desirable mutants.

The probability, $\mathrm{P}_{11}^{\mathrm{II}}$, is shown in the following equation $(\mathrm{I})$ :

$$
\mathrm{P}_{11}^{\mathrm{II}}=\mathrm{I}-\left[\mathrm{I}-\left\{p_{1}\left(\mathrm{I}-q_{2}^{n}-n p_{2} q_{2}^{n-1}\right)\right\}\right]^{m}
$$

This $\mathrm{P}_{11}^{\mathrm{II}}$ is, of course, zero when $n=\mathrm{I}$. Let $\mathrm{T}$ be

$$
\left|\log \left(\mathrm{I}-p_{1}+p_{1} q_{2}^{n}+p_{1} n p_{2} q_{2}^{n-1}\right)\right| \text {. }
$$

Then, relative $m, m n$ and $m+m n$ are obtained from equation (I) as $\mathrm{I} / \mathrm{T}, n / \mathrm{T}$ and $n+\mathrm{I} / \mathrm{T}$ regardless of any value of $\mathrm{P}_{11}^{\mathrm{II}}$. For calculating real $m, m n$ and $m+m n, \mathrm{I} / \mathrm{T}, n / \mathrm{T}$ and $n+\mathrm{I} / \mathrm{T}$ should be multiplied by $\left|\log \left(\mathrm{I}-\mathrm{P}_{11}^{\mathrm{II}}\right)\right|$ respectively.

Mutation in one locus is concerned in this report as well as in the previous ones in this series. Usually, $p_{1}=\mathrm{I} / \mathrm{1} 00$ and $p_{2}=\mathrm{I} / 5$ in rice, $p_{1}=1 / 740$ and $p_{2}=1 / 5$ in barley as described by Yoshida (1962). So that, the values of $p_{1}$ from $1 / 10$ to $1 / 10,000$ used for the calculations in table I may be expected with far wider ranges than those occurred actually in cereals. When $q_{2}=4 / 5$ and $p_{1}=\mathrm{I} / \mathrm{I}$ o to $\mathrm{I} / \mathrm{I} 0,000$, relative $m n$ and $m+m n$ obtained from $n / \mathrm{T}$ and $n+\mathrm{I} / \mathrm{T}$, respectively, in terms of $p_{1}$ and $n$ are tabulated in table $\mathrm{I}$. The ratios in per cent. of $m n$ and $m+m n$ when $n$ varies, to $m n$ and $m+m n$ when $n=2$ respectively, are also shown in table $\mathrm{I}$. The values of the ratio under given $n$ are almost constant in $m n$ and in $m+m n$ when $p_{1}=1 / 10$ to $\mathrm{I} / \mathrm{I} 0,000$ and $q_{2}=4 / 5$.

The rclative $m$ can be obtained by subtracting $m n$ from $m+m n$ in table $\mathrm{I}$. The value of $m$ is largest when $n=2$ and shows the monotone decrease with the increase of $n$, especially $m$ which comes nearer to $n=2$ decreases distinctly, that is, the ratios are 100,37 to $38,15,6 \cdot 9$ to $7 \cdot \mathrm{I}, 4 \cdot \mathrm{I}$ to 4.3 and 3.8 to 4.0 corresponding to $n=2,3,5,9,20$ and 50 respectively, when $\mathrm{I} / \mathrm{IO} \geqq p_{1} \geqq \mathrm{I} / \mathrm{I}$,ooo.

In table I the values of $m n$ dccrease with the increase of $n$, arc at a minimum for $n=9$ and increase with the increase of $n$. The values of $m n$ corresponding to $n=7$ to I 2 are not so much different from the minimum. The ratios are $\mathrm{I}$ oo for $n=2,32$ to 33 for $n=7,31$ to 32 for $n=9,32$ to 33 for $n=12$ and 95 to $\mathrm{I}$ oo for $n=50$. 
With respect to $m+m n$ in table I, the values of $m+m n$ decrease with the increase of $n$, are at a minimum when $n=10$ and increase with the increase of $n$. However, the values of $m+m n$ corresponding to $n=8,9$, I0, I 2 and I 3 are not so much different from the smallest. The ratios are 100 for $n=2,24$ for $n=8,23$ to 24 for $n=10,23$ to 24 for $n=13$ and 65 to 68 for $n=50$.

The smallest $m n$ and $m+m n$ are found for $n=I$ I and I 2 respectively, when $p_{1}=\mathrm{I} / 2$ and $q_{2}=4 / 5$ although $p_{1}=\mathrm{I} / 2$ is omitted in table $\mathrm{I}$ and the smallest $m$ is not found for $n=9$ when $p_{1}=\mathrm{I} / \mathrm{I} 0$ to I $/ \mathrm{I} 0$,000 and $q_{2}=4 / 5$. Judging from the fact that $p_{1}=1 / 100$ in rice and $p_{1}$ $=\mathrm{I} / 740$ in barley and that the important factor is not $m$ but $m n$, the method corresponding to $n=9$ is much better and the methods corresponding to 8 to 12 are better for the purpose of detecting at least one $\mathrm{X}_{2}$-line with at least two desirable mutants with the smaller number of total $\mathrm{X}_{2}$-plants, and/or $\mathrm{X}_{1^{-}}$and $\mathrm{X}_{2}$-plants in the aggregate. The methods corresponding to $n=8$ to 12 are here called the " improved ear-to-row method II " (method B II) consisting of methods B $\mathrm{II}_{8}$, $\mathrm{B} \mathrm{II}, \mathrm{B} \mathrm{II}_{10}, \mathrm{~B} \mathrm{II}_{11}$ and $\mathrm{B} \mathrm{II} \mathrm{I}_{12}$ corresponding to $n=8,9$, Io, I I and 12 respectively.

(iii) One-plant-one-grain method II (method C II), one-plant-two-grain method II (method D il) and one-plant-three-grain method II (method E II)

The effective procedures will be established by considering $\mathrm{P}_{12}^{\mathrm{II}}$ or $\mathrm{P}_{13}^{\mathrm{II}}$ for the purpose of detecting at least two $\mathrm{X}_{2}$-lines (which contain at least one desirable mutant per line) among $m$ lines or of detecting at least two desirable mutants from the whole of an $\mathrm{X}_{2}$-population.

$\mathrm{P}_{12}^{\mathrm{II}}$, the probability of detecting at least two $\mathrm{X}_{2}$-lines containing at least one desirable mutant per line among $m$ lines, is first furnished.

$\mathrm{P}_{12}^{\mathrm{II}}=\mathrm{I}-\left\{\mathrm{I}-p_{1}\left(\mathrm{I}-q_{2}^{n}\right)\right\}^{m}-m\left[\mathrm{I}-\left\{\mathrm{I}-p_{1}\left(\mathrm{I}-q_{2}^{n}\right)\right\}\right]\left\{\mathrm{I}-p_{1}\left(\mathrm{I}-q_{2}^{n}\right)\right\}^{m-1}$

When $q_{2}=4 / 5, p_{1}=1 / 10$ to $1 / 10,000$ and $\mathrm{P}_{12}^{\mathrm{II}}=0.95$ and 0.99 , the values of $m$ were calculated from equation (2). But the table is omitted here for want of space since they can be obtained by subtracting $m n$ in table 2 from $m+m n$ in table 3 . The values of $m$ decrease with the increase of $n$, especially $m$ which comes nearer to $n=1$ decreases distinctly. Therefore, when $n=\mathrm{I}$, the value of $m$ is largest.

In table 2, the values of $m n$ and the ratio in per cent. of $m n$ when $n$ varies, to $m n$ when $n=\mathrm{I}$ are shown when $q_{2}=4 / 5, p_{1}=\mathrm{I} / \mathrm{I}$ o to $I / I 0,000$ and $\mathrm{P}_{12}^{\mathrm{II}}=0.95$ and 0.99 . The values of the ratio for $\mathrm{P}_{12}^{\mathrm{II}}=0.95$ are equal to those for $\mathrm{P}_{12}^{\mathrm{II}}=0.99$ when given $p_{1}, p_{2}$ and $n$ are constant. The ratios generally increase with the decrease of $p_{1}$, but they are almost constant for any given value of $n$ when $p_{1}=1 / 10$ to I/I0,000. The lowest value of $m n$ is found under $n=\mathrm{I}$ since $m n$ shows the monotone increase with the increase of $n$ for a given value of $p_{1}$ from $\mathrm{I} / \mathrm{I} 0$ to $\mathrm{I} / \mathrm{I} 0,000$. This is applicable even when $p_{1}=\mathrm{I} / 2$. The relative values are I Oo for $n=$ I, I I to I I for $n=2$, I I I to I 23 for $n=3$, etc., when $p_{1}=1 / 10$ to $1 / 10,000$ as seen in table 2 . 


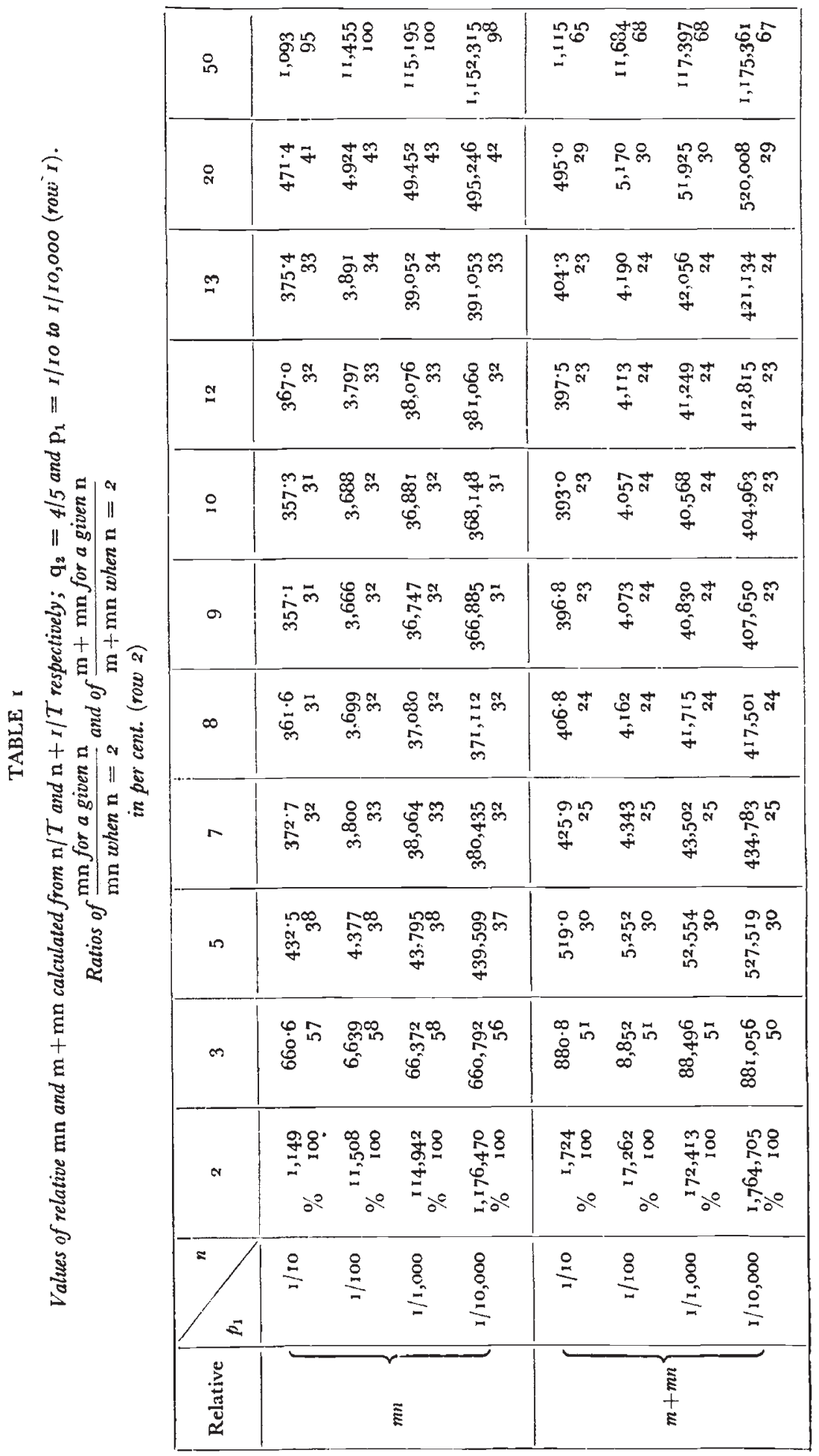




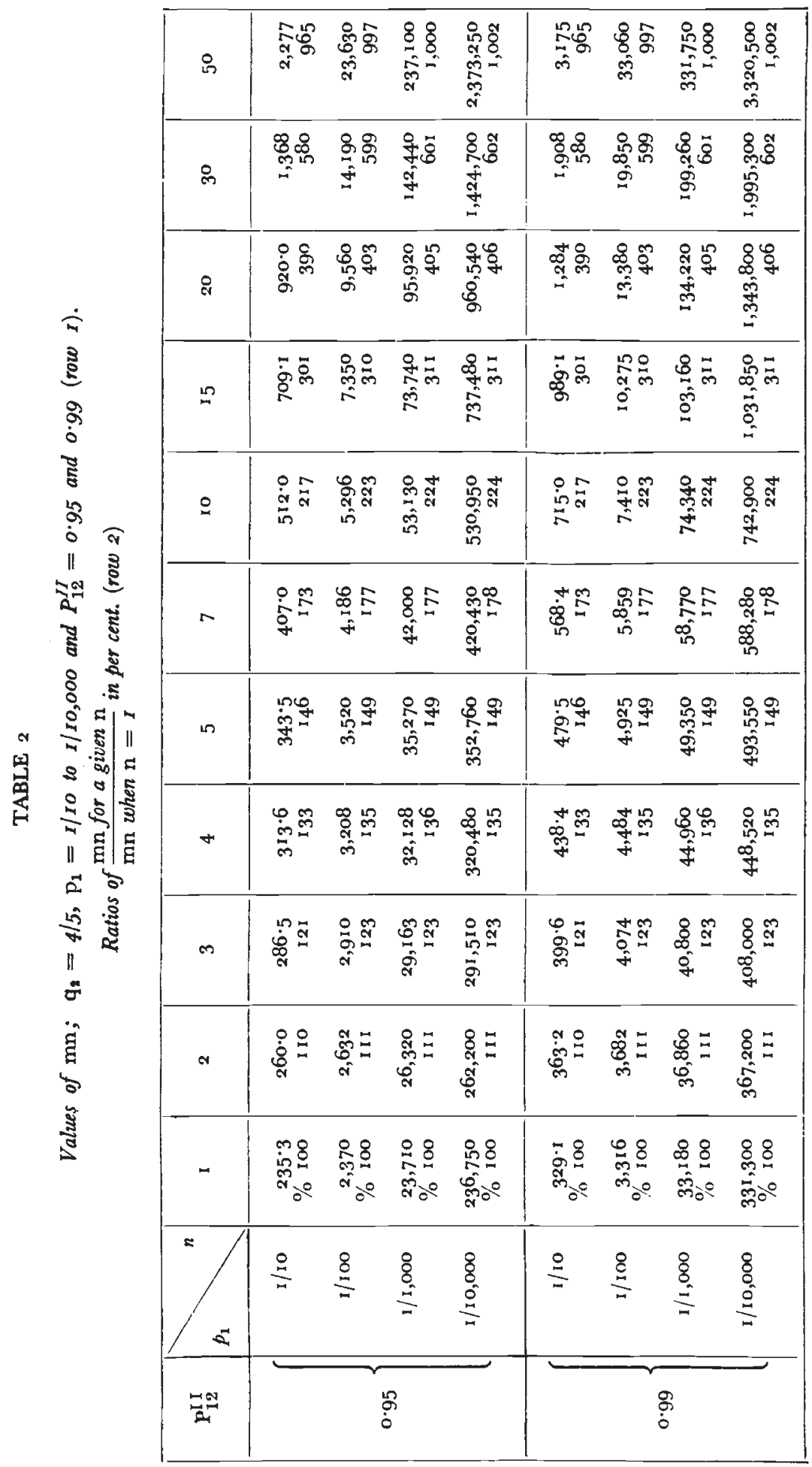


In table 3 , the values of $m+m n$ and the ratio in per cent. between $m+m n$ when $n=1$ and $m+m n$ corresponding to other values of $n$ are shown for different $p_{1}$ and $\mathrm{P}_{12}^{\mathrm{II}}$ respectively. The ratios increase with the decrease of $p_{1}$, but they are almost constant under the same $n$ when $p_{1}=1 / 10$ to $1 / 10,000$. In table 3 the ratios for given values of $n$ for $\mathrm{P}_{12}^{\mathrm{II}}=0.99$ are equal to those for $\mathrm{P}_{12}^{\mathrm{II}}=0.95$ when $p_{1}$ is constant.

As shown in table 3 , the value of $m+m n$ is smaller when $n=2$ and is at a minimum when $n=3$, and increases with the increase of $n$ for different values of $p_{1}$ from $1 / 10$ to $1 / 10,000$ and $\mathrm{P}_{12}^{\mathrm{II}}=0.95$ and 0.99 .

Then, the method corresponding to $n=\mathrm{I}$ needs the smallest $m n$ and the smaller $m+m n$, the method corresponding to $n=2$ needs the smaller $m n$ and $m+m n$, and the method corresponding to $n=3$ needs the smallest $m+m n$ and the smaller $m n$ for the purpose of detecting at least two $\mathrm{X}_{2}$-lines (which contain at least one desirable mutant per line) among $m$ lines. The method corresponding to $n=1,2$ or 3 is here designated the " one-plant-one-grain method II " (method C II), the "one-plant-two-grain method II" (method D II) and the "oneplant-three-grain method II " (method E II), respectively.

Methods C II, D II and E II can be established not only by adopting $\mathrm{P}_{12}^{\mathrm{II}}$ but also by adopting $\mathrm{P}_{13}^{\mathrm{II}}$ which represents the probability of detecting at least two desirable mutants among $m n$ plants and which was suggested by Dr Kudo. This $\mathrm{P}_{13}^{\mathrm{II}}$ is shown in the following equation (3):

$$
\mathrm{P}_{13}^{\mathrm{II}}=\mathrm{I}-\left\{\mathrm{I}-p_{1}\left(\mathrm{I}-q_{2}^{n}\right)\right\}^{m}-m n p_{1} p_{2} q_{2}^{n-1}\left\{\mathrm{I}-p_{1}\left(\mathrm{I}-q_{2}^{n}\right)\right\}^{m-1}
$$

For the same aim of detecting at least two desirable mutants in an $\mathrm{X}_{2}$-population, equations (2) and (3) are concerned from the standpoint of $\mathrm{X}_{2}$-line with at least one desirable mutant and of desirable mutant, itself, respectively. Needless to say, $\mathrm{P}_{13}^{\mathrm{II}}$ includes the case of detecting two desirable mutants not only in one $\mathrm{X}_{2}$-line but also two different $\mathrm{X}_{2}$-lines.

In table 4, the values of $m n$ and $m+m n$, the ratios in per cent. of $m n$ and $m+m n$ when $n$ varies, to $m n$ and $m+m n$ when $n=\mathrm{I}$ respectively, are shown when $p_{1}=\mathrm{I} / 10$ and $\mathrm{1} / \mathrm{10}, 000, q_{2}=4 / 5$ and $\mathrm{P}_{13}^{\mathrm{II}}=0.95$ and 0.99 . The results calculated from equation (3) shown in table 4 are quite similar to those from equation (2) shown in tables 2 and 3, with respect to the relation between $n$ and $m n$ or $m+m n$. The orders among methods C II, D II and E II obtained from equation (2) are the same with those obtained from equation (3), with regard to $m n$ and $m+m n$. This is applicable for the order among the methods for $m$.

\section{DISCUSSION AND CONCLUSION}

(i) Comparison of methods

For the purpose of detecting at least two desirable mutants in $\mathrm{X}_{2}$ with the smaller number of total $X_{2}$-plants, and/or $X_{1}$ - and $X_{2}$-plants in the aggregate, the four methods, B II, C II, D II and E II are established by considering three different probabilities, $\mathrm{P}_{11}^{\mathrm{II}}, \mathrm{P}_{12}^{\mathrm{II}}$ and $\mathrm{P}_{13}^{\mathrm{II}}$. 


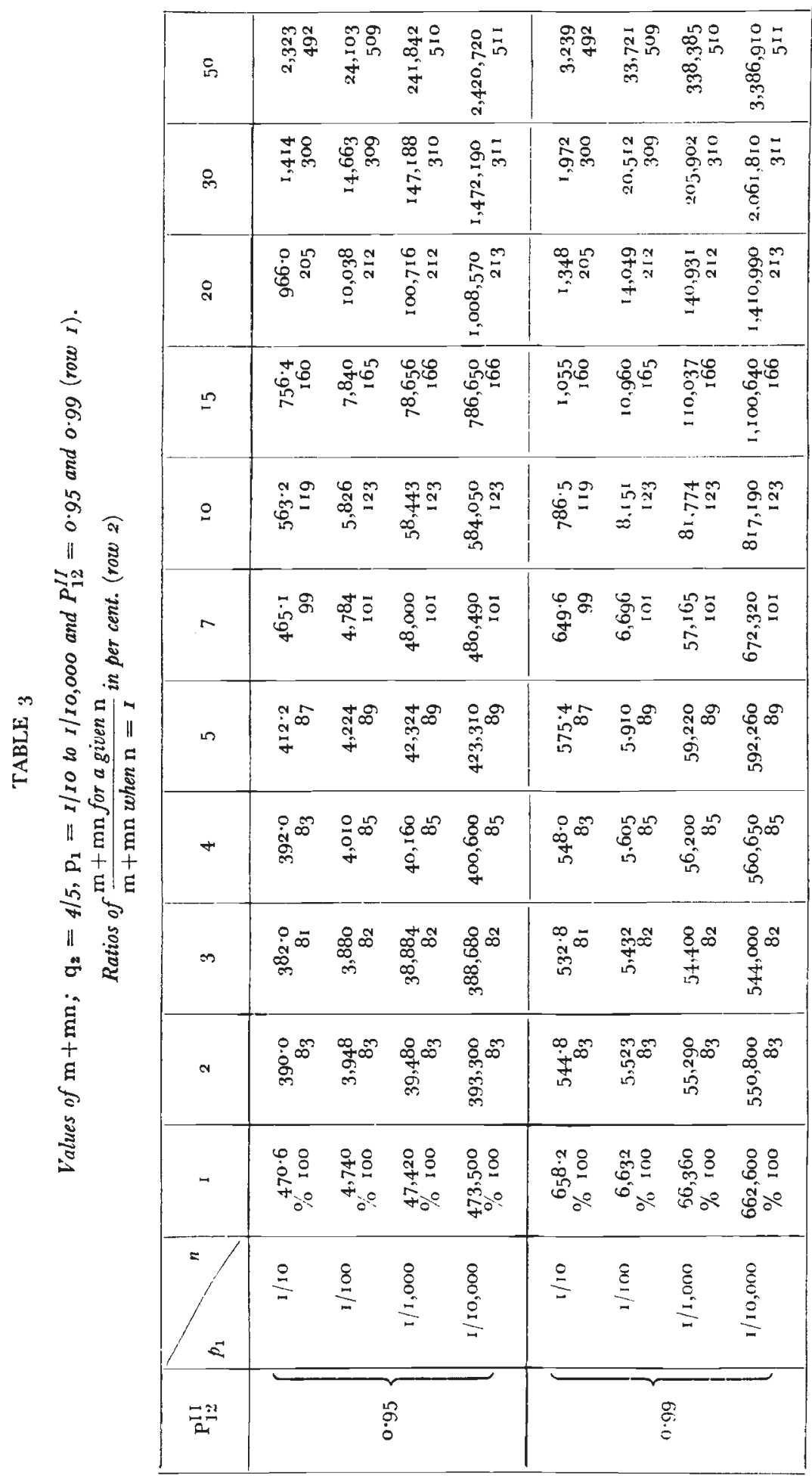




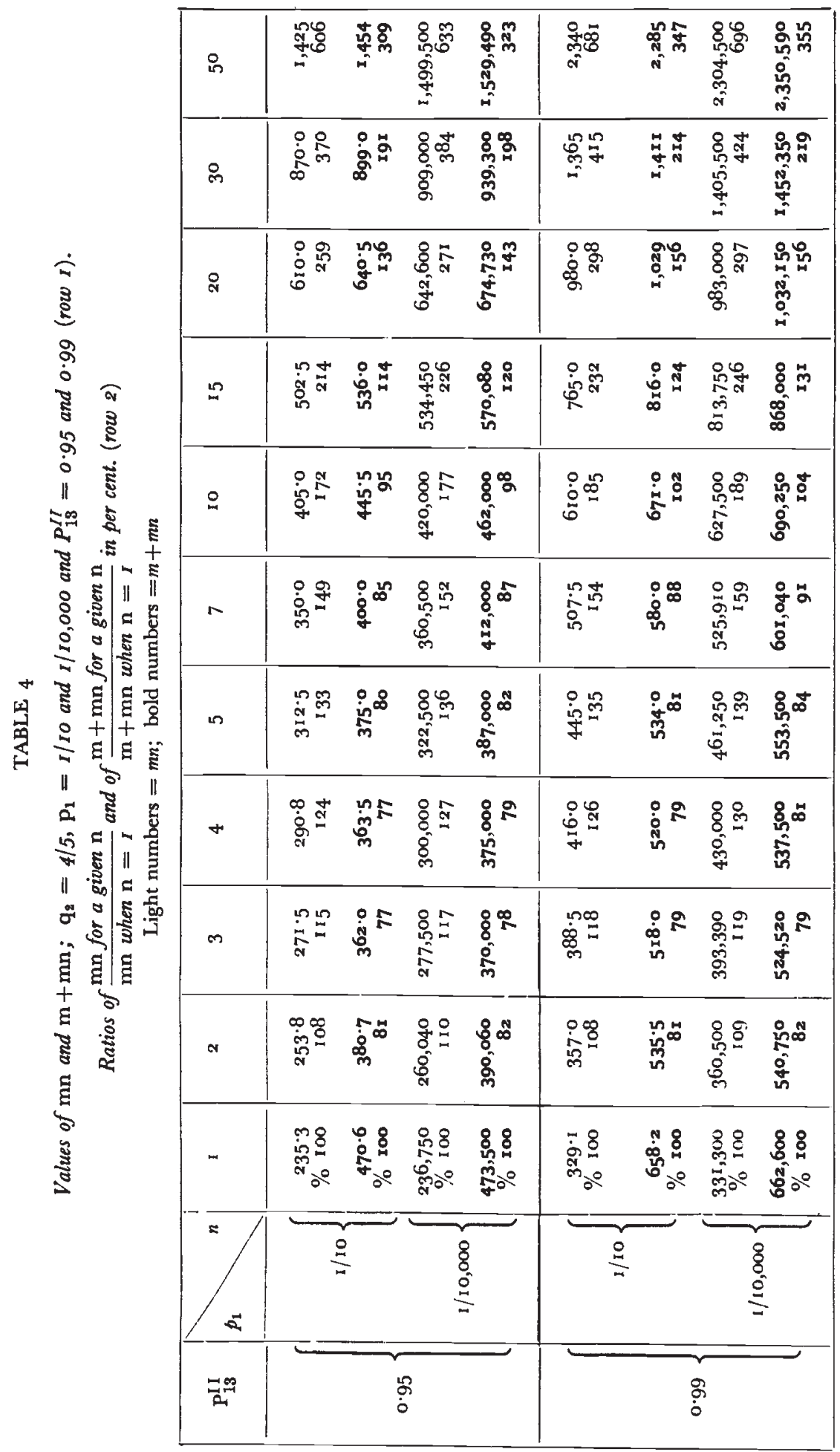


Method B II consists of method B II $, \mathrm{B} \mathrm{II}_{9}, \mathrm{~B} \mathrm{II}{ }_{10}, \mathrm{~B} \mathrm{II} \mathrm{II}_{11}$ and B II 12 which are established by considering $\mathrm{P}_{11}^{\mathrm{II}}$ and which are used as the ear-to-row methods. Method $\mathrm{B} \mathrm{II}_{9}$ is the most effective in method $\mathrm{B} I I$. In method $\mathrm{B} \mathrm{II}, \mathrm{I}_{\mathrm{g}}$, nine grains yielded from every one ear of the $\mathrm{X}_{1}$-plants of the number required for detecting at least one $\mathrm{X}_{2}$-line with at least two desirable mutants are sown to obtain corresponding $\mathrm{X}_{2}$-plants.

In methods C II, D II and E II which are established by considering $\mathrm{P}_{12}^{\mathrm{II}}$ or $\mathrm{P}_{13}^{\mathrm{II}}$ and which are used as the bulk-methods, one, two or three grains respectively, taken from every one ear of the $X_{1}$-plants of the number required to detect at least two $\mathrm{X}_{2}$-lines (which contain at least one desirable mutant per line) among $m$ lines or to detect at least two desirable mutants among $m n$ plants. The orders among methods GII, D II and E II obtained by considering $\mathrm{P}_{12}^{\mathrm{I}}$ are the same with those obtained by considering $\mathrm{P}_{13}^{\mathrm{II}}$ with respect to $m, m n$ and $m+m n$. However, the sizes of $m, m n$ and $m+m n$ calculated from equation (2) are larger than those calculated from equation (3) except those for $n=\mathrm{I}$, when constant $p_{1}, p_{2}$ and $n$ are given and $\mathrm{P}_{12}^{\mathrm{II}}=\mathrm{P}_{13}^{\mathrm{II}}$.

With regard to the number of grains taken from every one ear of the $\mathrm{X}_{1}$-plants, methods C II, D II and E II are identical with methods $\mathrm{C}, \mathrm{D}$ and $\mathrm{E}$ which are detected at least one desirable mutant in an $\mathrm{X}_{2}$-population as reported by Yoshida (1962). But the sizes of $m$, $m n$ and $m+m n$ in methods C II, D II and E II are larger than those in methods $\mathrm{C}, \mathrm{D}$ and $\mathrm{E}$, respectively.

Although the tables are omitted for want of space, the values of $m$ in the different methods will fall in the following order:

$$
\mathrm{C} \text { II }>\text { D II }>\mathrm{E} \mathrm{II}>\mathrm{B} \mathrm{II}_{9}
$$

where $>$ means "larger". Although $m$ is not so important in the practice of radiation breeding, it is necessary to prepare more $\mathbf{X}_{1}$-seeds in method C II than in other methods.

With respect to the values of $m n$, we have the following order from the values given in table $\mathrm{I}$ to $4: \mathrm{BII}_{9}>\mathrm{E}$ II $>\mathrm{D}$ II $>\mathrm{C} \mathrm{II}$. The value of $m n$ is very important in order to economise both labour and land in the practice of radiation breeding. The same order with $m n$ will be obtained for $m+m n$ when $X_{1}$ is planted densely and $\mathrm{X}_{2}$ is planted ordinarily. With respect to the values of $m+m n$, it is possible to have the following order from the values given in table $I$ to 4 :

$$
\mathrm{B} \mathrm{II}_{\boldsymbol{\theta}}>\mathrm{C} \mathrm{II}>\mathrm{D} \text { II } \gtrsim \mathrm{E} \text { II }
$$

where $\sim$ means "nearly equal".

\section{(ii) Application fields of methods B II, C II, D II and E II}

Yoshida (1962) described that when the discrimination of a mutant is difficult method $B$ will be useful and that when a mutant is easily distinguishable, method $\mathrm{C}$, with dense planting in $\mathrm{X}_{1}$, will frequently 
be much better and in some cases methods $\mathrm{D}$ and $\mathrm{E}$, especially $\mathrm{D}$, will be more useful in the practice of radiation breeding than method C.

Each of methods B II 9 , C II, D II and E II will be applicable in radiation breeding. However, no single method is known to cover all the advantages in the methods, each being superior to the "conventional ear-to-row method".

The following application fields of the methods to the practice of radiation breeding will be concerned. When the discrimination of a desirable mutant is very difficult, method $\mathrm{B} \mathrm{II}_{9}$ will be useful because at least two homozygous a $a$ plants in an $\mathrm{X}_{2}$-line can be detected under given probability. Methods $\mathrm{B} \mathrm{II}_{8}, \mathrm{~B} \mathrm{II}_{10}, \mathrm{~B} \mathrm{II}_{11}$ and $\mathrm{B} \mathrm{II} \mathrm{I}_{12}$ are also useful because $m n$ and $m+m n$ are not so much different from method $B \mathrm{II}_{9}$. When the discrimination of a desirable mutant is not so easy as methods C, D and E can be used or when it is desired to increase an expectation of the number of desirable mutants to be found in methods C, D and E, methods C II, D II and E II, with dense planting in $\mathrm{X}_{1}$, will be applicable instead of methods $\mathrm{C}, \mathrm{D}$ and $\mathrm{E}$ respectively, for the purpose of decreasing chance of losing desirable mutants to ensure the object of radiation breeding.

\section{SUMMARY}

I. The aim is to establish effective selection procedures by which two or more desirable mutants in the $\mathrm{X}_{2}$-generation following seed irradiation can be detected in a minimum total of $\mathrm{X}_{2}$-plants or of combined $\mathrm{X}_{1^{-}}$and $\mathrm{X}_{2}$-plants.

2. Four methods are considered which achieve this aim, they are:

(i) improved ear-to-row method (B II),

(ii) one-plant-one-grain method (C II),

(iii) one-plant-two-grain method (D II) and

(iv) one-plant-three-grain method (E II).

These methods have been evaluated by reference to the probability of

(i) detecting at least one $\mathrm{X}_{2}$-line containing two or more mutants,

(ii) detecting at least two $\mathrm{X}_{2}$-lines each containing one or more mutants and

(iii) detecting at least two mutants in the whole $\mathrm{X}_{2}$ population.

3. No single method is clearly superior to the other three in all respects but all four methods are superior to the conventional ear-to-row method in overall efficiency.

Acknowledgments.-The author is greatly indebted to Dr A. Kudo for his helpful suggestions and valuable criticism and to $\mathrm{Dr}$ C. Shigemura, Dr T. Koyama and Dr T. Nagamatsu for their critical reading of the manuscript. 


\section{REFERENCES}

GAUL, H. 1958. Present aspects of induced mutations in plant breeding. Euphytica, $7,275-289$.

мувом, N. 1954. Mutation type in barley. Acta Agric. Scand., 4, 430-456.

NishimURA, Y. 1954. Mutation breeding. Ikushugaku-kakuron, Yôkendo, Tokyo (in Japanese).

YoshIDA, Y. 1962. Theoretical studies on the methodological procedures of radiation breeding. I. New methods in autogamous plants following seed irradiation. Euphytica, 1 I, 95-III.

YOSHIDA, Y. 1964. Theoretical studies on the methodological procedures of radiation breeding. II. Expectation of the number of desirable mutants with the new methods. Euphytica, I3, 65-74. 